\title{
EL ORIGEN Y EVOLUCIÓN DE LA GLOBALIZACIÓN LITERARIA EN LA LITERATURA ESPAÑOLA
}

\author{
Origin and evolution of globalization in the spanish literature
}

\section{Benito Gómez Madrid*}

\begin{abstract}
RESUMEN
Para comprender la producción literaria de la España post-hegemónica resulta imprescindible tener en cuenta los efectos que ejerce el proceso homogeneizador que hoy se conoce como globalización. La tensión que registran estas obras a nivel estilístico no se puede justificar exclusivamente como una reaccion de estos autores a una crisis meramente personal, sino más bien como producto de una situación literaria que comparten en general todos los escritores pertenecientes a una sociedad marginal. Esta angustia, sin embargo, no tiene por qué interpretarse peyorativamente, ya que puede servir para inducir una renovación estilística. El primer y más evidente síntoma de esta tensión se revela generalmente a través de la aparición en el texto de la hibridez entre componentes tradicionales propios y vanguardistas europeos.

Palabras clave: hibridez, literatura española, marginalidad, nacionalismo, globalización
\end{abstract}

\begin{abstract}
In order to be able to fully comprehend the nature of Spanish literature after the decline of its empire, its crucial to take into account the effects caused by what today is known as globalization. The tension experienced by authors that are no longer able to exercise international influence is not personal, but the result of belonging to a society now in the cultural margins. This anxiety need not be interpreted negatively, since it can help to produce a literary renovation. The first and most obvious symptom of this tension generally appears as a hybridity of Spanish traditional components and fashionable European ones.

Key Words: Hibridity, Spanish Literature, marginality, nationalism, globalization.
\end{abstract}

Profesor en California State University- Domínguez Hills. Estados Unidos.

Correo electrónico: bgomez@csudh.edu

Recepción: 04/03/2014. Aceptación: 30/06/2014. 
Los procesos globalizadores han existido desde la antigüedad. La introducción del alfabeto en Mesopotamia, el uso de la moneda por los fenicios, o el sistema legal romano, constituyen ejemplos de este procedimiento integrador que generalmente se ha percibido como práctico y por lo tanto ha sido valorado positivamente. En el ámbito cultural, sin embargo, estas prácticas han ocasionado más pólemica según el nacionalismo demarcaba las identidades de los países y exacerbaba las diferencias entre las comunidades. A medida que se problematizaba la identidad, la controversia entre tradición e innovación estigmatizaba decisivamente los discursos literarios. Este proceso, tan extendido por todo Hispanoamérica, y el mundo en general, posee un origen que se puede detectar en la España de hace tres siglos, cuando esta pasa vertiginosamente de ejercer un rol hegemónico a padecer sus efectos, los cuales comienzan a acentuarse entretanto se plasmaba su progresiva pérdida de supremacía y se evidenciaba la interferencia de una significativa reacción defensiva nacionalista por parte de sus intelectuales. Mientras que decrecía su hegemonía política, la influencia española en el desarrollo cultural europeo se reducía gradualmente. La nación que surge del aislamiento ideológico de la Contrarreforma y de las humillantes condiciones del tratado de Utrech, ya no es la potencia respetada de los dos siglos anteriores. De forma paulatina pero traumática estaba adaptándose a desempeñar un papel secundario en el devenir de los acontecimientos históricos ${ }^{1}$. Con la llegada de la dinastía de los Borbones y la desaparición de las últimas genialidades individuales de los maestros del Siglo de Oro, los intelectuales españoles de principios del siglo XVIII enfrentan su futuro dubitativamente y desde una posición cada vez más periférica.

Generalmente, a la etiqueta de marginalidad se le otorga una connotación negativa. No obstante, conviene resaltar que en los últimos trescientos años las sociedades en los márgenes de lo que hoy se conoce como globalización han realizado una inmensamente productiva tarea de resistencia frente a los procesos aglutinadores de las sociedades hegemónicas que, de forma más o menos intencional, intentan borrar las diferencias entre culturas e imponer sus modelos interpretativos a sociedades menos fuertes. El proceso de adquisición de agencialidad por parte de las literaturas periféricas ha resultado arduo pero no necesariamente infructuoso. En ciertas ocasiones, se comete el error de comparar la literatura de una sociedad periférica con la de una globalizadora usando parámetros interpretativos configurados por el discurso hegemónico. En estos casos, la literatura de países latinoamericanos, o la de España en los últimos tres siglos, nunca se ajusta totalmente a ellos y por tanto se considera incompleta o anómala. Sin embargo, si consideramos el originalísimo proceso de creación al que se somete un escritor marginal en su esfuerzo por ser aceptado por la sociedad globalizadora, el análisis produce unos resultados más satisfactorios. Aunque el reconocimiento de la posición de marginalidad se realiza en muchas ocasiones a regañadientes, o incluso se rechaza abiertamente, es indudable que en el caso de España sus intelectuales tratan de crear un estilo que sincronice su literatura con las modas europeas a la vez que conecte con su glorioso pasado intentando incorporarse a las directrices de las sociedades hegemónicas en los últimos tres siglos agregando ideas fóraneas e hibridizando progresivamente su propia identidad.

La posibilidad de los grupos marginales de obtener voz propia es un tema discutido con intensidad $^{2}$. Irónicamente, la mayor parte de los debates han surgido desde las sociedades globalizadoras, donde realmente no existe esta problemática. La consideración canónica de una obra no se produce por razones esencialistas de carácter ahistórico, sino como consecuencia de una serie de factores políticos y económicos que constituyen el complejo entramado de la globalización, la cual se encuentra siempre en continuo proceso de transformación. Los textos de las sociedades periféricas forman parte de un proceso general e inclusivo que debe permitir considerarlos no solo como anómalos 
o desviaciones del canon hegemónico ${ }^{3}$, sino como productos interesantes, atractivos $\mathrm{y}$ necesarios para comprender un complejo mundo de correspondencias culturales que se rige por una ineludible globalización. Cualquier otra aproximación conduce inevitablemente a una percepción restrictiva del fenómeno estético al aproximarse a su intrincada dinámica con una perspectiva limitada.

En los últimos siglos, las sociedades hegemónicas, utilizando un discurso globalizador, han justificado sus invasiones militares con el pretexto de beneficiar a las sociedades más atrasadas y "civilizarlas." Pero la globalización ha afectado a todas las sociedades, incluida la española, aunque no siempre se haya producido colonización militar y económica. Como aclara José Ortega y Gasset, no todas las invasiones militares constituyen necesariamente una colonización, solamente cuando se produce como cambio de espacio a una tierra culturalmente más "joven," ya que cada territorio se encuentra en una localización espacial y temporal determinada, en un cierto estado de civilización o "cultivo," que depende de los habitantes autóctonos que la pueblen. Cuando se lleva a cabo una colonización, "hombres de pueblos viejos y muy avanzados en el proceso de su civilización caen en tierras menos civilizadas, es decir, históricamente más jóvenes [. . .] Lo que esta tierra tiene de nueva es que, relativamente a las capacidades del emigrante, está vacía" (1983: 373). La colonización cultural que Francia realizó sobre la península no fue necesariamente consecuencia directa de una invasión militar como la de Napoleón, ni tan siquiera de la llegada de la dinastía borbónica al trono español, ya que como va a apuntar Ortega, no es necesario invadir militarmente para "colonizar" culturalmente a un pueblo (1983: 373-74).

En este sentido, la teoría postcolonial puede servir para analizar la problématica de naciones que exhiben una dependencia cultural de sociedades globalizadoras. Críticos como Arif Dirlik afirman que una "conciencia post-colonial" podría haber existido antes de que se acuñara el término y que los orígenes de la situación postcolonial provienen específicamente del "Primer Mundo." Dirlik demuestra cómo si la postcolonialidad ha sido desconectada del concepto del Tercer Mundo, la consideración de una sociedad como marginal se fundamenta en factores de poder y desarrollo (1994: 332). "La diferencia" que se observa en las obras periféricas con relación al discurso globalizador posee la connotación peyorativa de subordinación. Sin embargo, desde el punto de vista de las sociedades periféricas, la diferencialidad se considera una seña de identidad que posibilita la adquisición de una voz propia. La teoría post-colonialista se centra en la necesidad de ciertas sociedades marginadas de construir una identidad independiente y estudia los esfuerzos por parte de sus intelectuales por introducir en el canon de la globalización interpretaciones propias que contribuyan a superar las diferencias entre roles primarios y secundarios, así como otras formas binarias de interpretación. Posiblemente uno de los conceptos en los que se fundamenta la base de la teoría postcolonialista con más fuerza sea el de eliminar los sistemas binarios en la comprensión de las diferencias culturales utilizados por las sociedades globalizadoras para realizar una conceptualización maniquea del mundo ${ }^{4}$.

La escritura del autor periférico está condicionada en gran medida por su relación con la sociedad globalizadora. No obstante, su producción artística también afecta a la cultura hegemónica. La ambivalencia, la hibridez, o el "mestizaje" de cualquier tipo (racial, cultural, etc.) siempre ha provocado sospecha o ansiedad y han sido regularmente suprimidos de la obras producidas en las sociedades hegemónicas. Sin embargo, los autores en la periferia de los movimientos globalizadores van a recurrir a la introducción de estos elementos justamente para subvertir las estructuras binarias que se les imponen. La relación entre ambos elementos no ocasiona una influencia unilateral, sino más bien un proceso de transculturación. De manera similar a la planteada por Saussure respecto a la lengua, donde los signos adoptan un significado como oposición a otros signos; las culturas adquirirían significado como oposición a otras culturas. Una cultura nunca permanece estática, 
sino ambivalente, cambiante y abierta a posibles interpretaciones futuras. En este espacio híbrido se desarrolla la identidad cultural, la cual contiene rasgos de otras identidades y de identidades pasadas. Al observar estos procesos, se descubre la necesidad de elaborar formas alternativas de independización e individuación ${ }^{5}$. Los escritores periféricos intentan cuestionar el proceso de "normalización" que llevan a cabo los intelectuales hegemónicos, quienes utilizan sus propios parámetros para juzgar a sus sociedades.

Inicialmente, el uso de teorías feministas, marxistas, etc., se consideró inadecuado para tratar con las peculiaridades de las sociedades periféricas, al estimarse que dichas teorías provenían de otras tradiciones culturales y respondían a diferentes preocupaciones. El problema que se encontraba en estas teorías consistía en que generalmente tendían a utilizar nociones globalizadoras de la cultura que asumían sus concepciones filosóficas y lingüísticas como universales. Los escritores marginales van a procurar subvertir estas concepciones incorporando principios de acción de múltiples escuelas de pensamiento que comparten el objetivo de atacar sistemáticamente el logocentrismo centralizador de las grandes narrativas europeas de los países que ejerercen la globalización. Los textos de autores pertenecientes a sociedades en los márgenes de la globalización van a desmantelar el binarismo centro/margen desde una localización cultural híbrida a través del uso de estrategias subversivas como la imitación, la parodia o la ironía.

Elinicio de una conciencia de marginalidad en la península ibérica se detecta con bastante claridad desde el siglo XVIII, cuando ciertos sectores de la intelectualidad española pidieron una globalización a todos los niveles del país, siguiendo modelos globalizadores de desarrollo de la Francia de la Ilustración. Sin embargo, según se observa en sus obras, se podía advertir cómo aún continuaban aferrados a una tradición que les permitiera mantener, sin dañar su orgullo, una identidad propia. Hacia el final de este siglo, una minoría ilustrada, acusada por la oposición tradicionalista de afrancesamiento, intenta controlar la producción, distribución y recepción cultural. Se pretende centralizar la cultura y se equipara con Estado tratando de proporcionar unidad y homogeneidad. Usando como parámetros excluyentes el racionalismo, el progreso y la educación, se marginalizan todos los elementos que, en su opinión, no contribuyen al interés de la nación. Los autores ibéricos, sin dejar de ser patriotas, comienzan a reconocer su pertenencia a una sociedad vista en Francia como periférica, pero por la que sienten orgullo y vergüenza a la vez.

Escritores españoles de la época como Feijoo, Jovellanos, Forner y Cadalso van a preguntarse acerca del estado de su país, no solo laméntandose en términos quevedianos sobre la decadencia del imperio, sino situándose específicamente en comparación con el resto de Europa. A este respecto, es importante poner de relieve el generalizado convencimiento sobre la prominencia y superioridad de la Francia ilustrada, tomada en este momento histórico como modelo porque estaba intentando modernizar sus estructuras socio-políticas y porque se percibía como una nación "fuerte," asociando esa potencia a su modernidad ${ }^{6}$. La culminación de este proceso implica llevar a cabo un sistemático desprestigio del pasado y de todas aquellas sociedades ancladas en él. La misma Francia va a configurar su identidad como nación en vanguardia por excelencia y para poner en marcha tal proyecto desarrolla un discurso en el que considera como atrasadas ${ }^{7}$ al resto de sociedades que no sigan su estela por insistir en mantener sus costumbres ${ }^{8}$. La imposición de este modelo de cambio histórico resulta como consecuencia de asignar un estado de pre-historia a las sociedades tradicionales y considerar inviable su desarrollo si no se produce a través de la incorporación de las ideas universales que auspicia la globalización ilustrada. De cualquier forma, el convencimiento por parte de los escritores progresistas de las sociedades periféricas de que estas ideas habían surgido en Francia y no en su sociedad provocaba serios reparos, ya que cualquier afiliación con ellas adoptaba la connotación de imitación. 
Las campañas militares de Napoleón en Europa van a propagar con rapidez un sentimiento nacionalista que afectará profundamente a la creación artística de los países subyugados que se afligen por su desventaja cultural y perciben su identidad amenazada por unos patrones de civilización impuestos por una sociedad extranjera. Normalmente, esta situación provoca que la sociedad periférica intente reformar su identidad para adaptarla a los valores de las más avanzadas reteniendo ciertos componentes propios, para lo cual es posible que se seleccionen ciertos períodos del pasado que interesa rescatar y se ignoren otros. El acontecimiento histórico ineludible de la invasión francesa va a forzar a muchos de los intelectuales hispanos a reconocer su pertenencia a una sociedad en la periferica cultural y consecuentemente a decantarse entre tomar una posición a favor o en contra de los modelos franceses 9 . El primer impulso de las sociedades periféricas, mediatizado por el deseo de ser aceptadas y consideradas iguales, se va materializar en la emulación de la cultura globalizadora, aunque sea disfrazándola con prácticas y modelos tradicionales.

A pesar de los intentos de ciertos escritores españoles "ilustrados" de incorporarse a las fuerzas globalizadores de la Ilustración francesa, todavía durante el Romanticismo España es percibida desde el exterior como una sociedad fiel a su tradición, sin modernizar ${ }^{10}$, un país exótico que levanta curiosidad en ciertos sectores de Europa que ya no valoran la globalización tan positivamente. Estas facciones van a intentar poner de moda un distanciamiento crítico del mercantilismo burgués y a insistir nostálgicamente en valorar el supuesto desdén por los bienes materiales del español, así como la espontaneidad y el gozo de la vida de una cultura más primitiva. A los intelectuales extranjeros, pertenecientes a sociedades más avanzadas, no les interesaba comprender la España real, y su sentimiento de curiosidad o aprecio hacia la nación ibérica no desmiente en modo alguno su sentido de pertenencia a una sociedad superior. Los viajeros franceses e ingleses, guiados por unos estereotipos predeterminados en sus países, solo encuentran en la península las imágenes que desean ver. Sin embargo, las impresiones de estos intelectuales alterarán profundamente la percepción de España fuera y dentro de la península. Con la reacción antinapoleónica en España se revisa la tradición y se recupera el Siglo de Oro. Autores como Byron, Hugo y Merimée la idealizan, convirtiéndola en un país de valientes y de apasionados, pero también de bandidos, representando a sus habitantes como gente siempre cercana a la muerte e indiferente a ella.

Al mismo tiempo, la politización del Romanticismo va a potenciar en el terreno literario ciertas posturas nacionalistas. Mientras se acentúa la preocupación por el problema de las identidades nacionales es posible observar en los autores españoles una mayor resistencia contra la globalización y un deseo de recuperación de la tradición española. Este tipo de nacionalismo surge como reacción a la manipulación cultural de la globalización del fuerte y la pérdida de carácter que conlleva en el dominado. Sin embargo, el proceso puede resultar en sí mismo original y sumamente útil para el subyugado ya que este nacionalismo se nutre de características propias y permite a los grupos marginales elaborar discursos alternativos afirmando su diferencialidad creativa contra el absorbente poder de la globalización, caracterizada por su naturaleza asimiladora. La oposición a ella se convierte en una actitud de vital importancia para estos escritores, ya que perciben acertadamente que su pretensión unitaria y homogénea es empleada como factor discriminador. Los escritores periféricos, reaccionan contra la asunción de que los grandes escritores pertenecientes al canon son aquellos capaces de transmitir sentimientos universales. A este respecto se preguntan quién ha determinado cuáles son esos sentimientos. La realidad, van a proponer, es que las sociedades hegemónicas han equiparado las características de sus concepciones particulares con las de la globalización.

El nacionalismo trata de revertir la forma de proceder del pensamiento globalizador, intentando atribuir agencialidad a las naciones marginales y enunciar la capacidad para realizar 
una acción autónomamente, sin verse afectada por la forma en que se construye la identidad periférica por presiones externas. El simple reconocimiento de esas fuerzas supone una resistencia a la imposición globalizadora y posibilita la reacción defensiva. Entendido así, el nacionalismo puede resultar beneficioso para las sociedades periféricas ya que propicia la elaboración de alternativas propias al discurso globalizador de gran originalidad. Debido a que la intensificación del nacionalismo coincide temporalmente con la inminente ascendencia de la novela en el siglo XIX, el uso de este género posibilita la reproducción de las estructuras de la nación, permitiendo a los intelectuales periféricos, en palabras de Benedict Anderson, "imaginar una comunidad ideal $^{11}$."Para la segunda mitad del siglo XIX, cuando el movimiento realista se pone de moda en Francia y consecuentemente en Europa, algunos de los escritores españoles expresan un deseo de reconciliar la tradición española con los movimientos de moda franceses, estableciendo puntos en común; o de desviar la ansiedad de influencia, sugiriendo que la inspiración proviene de Rusia ${ }^{12}$, o de Alemania, y no de Francia.

El cuestionamiento del concepto globalizador de las nociones estéticas que se había iniciado durante el Romanticismo había beneficiado a las sociedades marginales al proporcionarles una justificación para subvertir las bases de la modernidad. Durante el siglo XIX se produce, sin embargo, la expansión colonial europea. Colonialismo globalizador y discurso particularista conviven a lo largo de un siglo caracterizado por la intensificación de la lucha entre globalización y localismo que se se llevó a cabo desde el siglo XVIII. Estas dos concepciones de modernidad conviven en constante agresión. Matei Calinescu apunta a una separación en la idea de modernidad que surgió a mediados del siglo decimonónico cuando se produjo la aparición de dos conceptos opuestos: "modernity as a stage in the history of Western civilization-a product of scientific and technological progress, of the industrial revolution, of the sweeping economic and social changes brought by capitalism-and modernity as an aesthetic concept" (1987: 41). A partir de estos momentos resulta imposible negar la evidencia de la paulatina globalización de la cultura siguiendo unos parámetros occidentales; no obstante, tampoco se puede obviar la progresiva recuperación por parte de las culturas periféricas de una conciencia marcada por su poder de subversión, dando inicio a un belicoso proceso de influencia recíproca que sin embargo permite "[a] variety of mutual influences in their rage for each other's destruction" (1987: 41).

En las últimas décadas del siglo XIX, mientras que en Europa los nuevos movimientos se centran en los conflictos sociales derivados del proceso de globalización, en España se reflejará una gran preocupación por confrontar problemas de identidad nacional, convirtiéndose en asunto de capital importancia la retención de la tradición. Laura Otis ha explicado el origen de este proceso, que comienza en el siglo XIX, y cómo marca la dinámica de formación identitaria del período de entresiglos: "when the present is unbearable, as in Germany in 1918 or in Spain in 1898, one looks for one's essence in the past. In this tendency to seek identity through history, the organic memory theory was closely associated with nationalism. It evolved in the nineteenth century in parallel with nationalism, when identity was a pressing issue" (1994: 97). Esta diferencialidad de la sociedad española solo se puede achacar a que, a pesar de que llevan doscientos años padeciendo este síndrome de marginalidad, para finales del siglo XIX, los intelectuales españoles han llegado a la conclusión ineludible de que su país no forma parte de las sociedades que influyen en la globalización.13

Tras un siglo de dependencia cultural de Francia, el "desastre" de 1898 va a afectar profundamente el orgullo nacional español y a producir una comprensible crisis de identidad que conducirá a una polarización en la política y la cultura. Francisco Caudet es quizá uno de los críticos que mejor ha señalado la particularidad nacionalista del debate cultural que se desarrolló durante los años 1870 a 1880 en España, explicando una de las reaccciones 
más interesantes: "El rechazo, total o parcial, del naturalismo, fue acompañado de una toma de conciencia nacionalista. Progresivamente se fue argumentando que la cuna del realismo y del naturalismo no estaba en Francia sino en España" (1994: 522). La creciente conciencia de dependencia cultural del país vecino propicia el incremento de mecanismos de defensa. Según Caudet, los escritores españoles, resistiéndose aún a reconocer su situación, reaccionaron defensivamente contra su incómoda posición de seguidores, tratando de asignar un origen español al Realismo y citando como antecedentes de ese movimiento a la novela picaresca y las obras de Cervantes:

Se empezó a tomar conciencia de que España dependía culturalmente de Francia. Todo lo cual explica que aparecieran unos mecanismos compensatorios, tendentes a potenciar la idea de que existía una tradición realista autóctona, en la que irónicamente se hallaban articuladas las bases de la 'escuela naturalista' francesa. ¿Quién influía a quién? ¿De quién era la dependencia cultural? Así las cosas, en la querella naturalista se introducía un factor nacionalista. (1988: 64)

Estas circunstancias sirven para aclararar por qué escritores españoles supuestamente naturalistas, como Emilia Pardo Bazán, solamente aceptaran una versión filtrada del movimiento francés (Gómez 2007). El producto resultante, que priva de algunos de sus componentes fundamentales al movimiento, provoca que se cuestione hasta qué punto es verdaderamente "realista". La alternativa española proponía una reinterpretación del movimiento francés que hibridizara los métodos galos con las técnicas novelísticas y contenidos ibéricos. Este procedimiento revela que los textos producidos en la periferia reflejan con frecuencia una voluntad de reinterpretar los productos de la globalización y plantear propuestas alternativas autóctonas ${ }^{14}$.

La resistencia a los modelos globalizadores puede realizarse no solo apelando a la tradición propia sino también recurriendo a tradiciones culturales alternativas. Tras la guerra Franco-Prusiana de 1870-71, mientras que los españoles proseguían inmiscuidos en una gran crisis político-social, los alemanes van alcanzando una posición de prestigio en Europa. Progresivamente, y en parte para sacudirse la acusación de influencia francesa, se produce desde España un acercamiento a la ideología germana, que verdaderamente ya se había iniciado desde principios de siglo con Nicolás Böhl de Faber. Esta aproximación acabará por fructificar años después en la adopción del krausismo ${ }^{15}$ por parte de un sector significativo de los intelectuales españoles. Con este movimiento se intenta la incorporación de España a Europa mediante la adaptación de una cultura racional alternativa a la francesa. La elección de ciertos intelectuales españoles de una filósofía relativamente oscura y sin trascendencia en Alemania podría parecer en principio arbitraria o carente de sentido. Esta repentina germanofilia ${ }^{16}$ solo se puede excusar por la profunda galofobia de los intelectuales españoles, causado por la percepción de una insoportable invasión cultural por parte del globalizador país vecino. De todas formas, la influencia gala no desapareció y continuó produciendo sentimientos ambiguos de resentimiento, admiración, examen de conciencia de la situación propia y nostalgia de un pasado hegemónico, todos ellos síntomas inequívocos de la influencia de la globalización.

El clima literario de la España de finales del XIX se caracteriza por una general insatisfacción. Los escritores del 98 parecen abogar por la implementación de una variedad de reformas en las obras literarias y en la prensa periódica. Aunque algunos, como Ganivet, Maeztu o Unamuno siguen haciendo referencia a menudo al "carácter español," en líneas generales se observa un intento de escape de las interpretaciones esencialistas para establecer puntos en común con las demás literaturas europeas y procurar una compaginación entre modernidad y tradición:

Todos buscan la apertura hacia Europa, de la que les vienen a todos la inspiración, las ideas, los modelos; pero al mismo tiempo, todos pretenden reanudar con una inspiración popular, cuya definición es sin duda ambigua pero central: tanto en arte como en filosofía, se trata de volver a una creación que sepa hacer suyos los legados de las tradiciones seculares, 
sin renunciar por ello a la capacidad innovadora del artista. (1988: 339)

Este proceso es comprensible y hasta predecible si se tiene en cuenta que los intelectuales de la España post-98 experimentan cada vez más acentuadamente la sensación de escribir en una nación marginal tanto a nivel político como cultural. Si durante los siglos XVIII y XIX la resistencia a los modelos hegemónicos europeos, fundamentalmente franceses, ya era evidente en numerosos escritores españoles ${ }^{17}$,a partir de 1898 la reacción se intensifica. Los autores españoles toman mayor conciencia de la dolorosa alternativa entre seguir escribiendo acorde a su tradición, pero al margen de las corrientes en boga en Europa; o adoptar los modelos de moda en Francia, con el riesgo de ser percibidos como meros emuladores de ideas surgidas de procesos globalizadores. Los hombres del 98 buscan una forma ingeniosa de escribir que no revele abiertamente influencias europeas y que contenga elementos que les permitan conservar una identidad propia. Como resultado de la dependencia cultural que experimentan, estos autores españoles se encuentran en una posición incómoda, en una localización extraña, desraízada, que va a precisar ser reconfigurada de nuevo.

A finales del siglo XIX parece acontecer un cambio en la concepción del arte del que se van a beneficiar las sociedades periféricas: comienza a valorarse de nuevo la pluralidad estética, la validez de estéticas alternativas a la europea. El modernismo europeo cuestiona la posibilidad de imitar la realidad de una sola forma, ya que disputa incluso la existencia de una realidad objetiva, única, por lo que el arte de las denominadas sociedades primitivas comienza a percibirse no como "atrasado" sino como distinto, original, interesante, en otras palabras: digno de ser globalizado. Para las culturas marginales las consecuencias de la nueva revolución estética van a producir inesperados resultados positivos:

[With modernism] Europeans were forced to realize that their culture was only one amongst a plurality of ways of conceiving of reality and lorganizing its representations in art and social practice. Central to this perception was the encounter with African culture in the period of the so-called 'Scramble for Africa' in the 1880s and 1890s. (1989: 156)

Este proceso va a contribuir a una sorprendente y revolucionaria configuración de las estructuras del discurso globalizador que se evidenciará en la aparición de una nueva tendencia estética: la imitación positiva consciente de obras internamente consideradas marginales. Esta apropiación y asimilación de un discurso globalizante por parte de las sociedades hegemónicas resulta de importancia capital para las sociedades periféricas, ya que posibilita una apertura de enfoque estético. La nueva concepción de la literatura, más amplia en su interpretación, les autoriza a apropiar elementos de las literaturas globalizadoras que les permitan una incorporación al canon.

La realidad socio-política obliga a los intelectuales periféricos a vivir entre dos culturas antagonistas. Escritores como los españoles, pertenecientes a una sociedad carente de influencia, se encuentran atrapados entre dos tendencias opuestas: una destinada a mantener un componente identitario que se caracteriza por el apego a elementos considerados "auténticamente españoles"; y la otra, motivada a incorporarse a la globalización, que surge de la necesidad en el autor periférico de que sus obras obtengan un reconocimiento internacional, aunque este se produzca como incorporación a una corriente estética de origen foráneo. El resultado de la urgencia en compaginar ambas tendencias produce que las obras escritas durante un período de dependencia cultural rebosen hibridez. Este fenómeno ya se aprecia desde el siglo XVIII en Feijoo o Cadalso, aunque más irregularmente y con menor frecuencia. Sin embargo, comienza a observarse más ostensiblemente a finales del XIX y a principios del XX. Esta intensificación es principalmente debida a la paulatina toma de conciencia por parte de los intelectuales españoles de su situación de inferioridad en las relaciones culturales entre naciones que causa la globalización.

La particularidad de este período se puede advertir con nitidez estudiando los textos de 
autores como Emilia Pardo Bazán, Pío Baroja o José Martínez Ruíz “Azorín"18”. Estos escritores van a producir obras de gran interés y riqueza hermeneútica, que se van a caracterizar por su hibridez. Un estudio exhaustivo de estas obras servirá para esclarecer el complejo proceso de la escritura en un mundo dominado por la globalización que impone sus modelos de concepción cultural. Los textos ambivalentes de estos autores, que se han conformado como una mezcla de ensayo, ficción, digresión filósofica, análisis psicológico, inserción histórica y alegoría nacionalista, poseen la capacidad de posibilitar una rica gama de interpretaciones, no solo heterogéneas, sino inéditas, con las cuales los escritores en los márgenes de los procesos globalizadores se han armado y se seguirán armando para generar agencialidad y un discurso alternativo que genere independencia y esperanza.

\section{Notas}

1. En 1648 termina la guerra de los Treinta Años. La pérdida de hegemonía política y militar de España, que queda económicamente en bancarrota, y además tiene que reconocer la independencia de Holanda, se puede comenzar a percibir ya desde este momemto. En 1814, tras el Congreso de Viena, España ya ni siquiera se encuentra entre las potencias participantes que deciden el futuro de Europa.

2. Spivak se ha preocupado por articular las contradicciones en la construcción de voz propia para el marginado afirmando que ningún acto de resistencia puede ocurrir de forma esencialista separada del discurso hegemónico, sino que utilizando la forma de expresión hegemónica, la cual es apropiada por el marginado para poder adquirir agencialidad (1990: 219-44). En el contexto latinoamericano, Jeffrey Cedeño señala que Borges fue en su tiempo icono nacional no solo argentino sino latinoamericano debido a que logró utilizar su propia tradición cultural y a la vez "postular una literatura en abierto y libre diálogo con la tradición occidental" (2006: 60). Pero para Cedeño hoy ha perdido esa capacidad y "se encuentra liberado a su suerte ante el poder desterritorializador de las identificaciones provisionales que convoca en buena medida la equivalencia general de los medios globales" (2006: 60).

3. Para Waïl S. Hassan, la literatura mundial tradicionalmente se ha asociado con la literatura europea, aunque recientemente, debido al reconocimiento de los premios Nobel y a la mayor disponibilidad de traducciones de escritores que no pertenecen a la cultura occidental se ha producido un cuestionamiento de la hegemonía del canon occidental. Sin embargo, este proceso acaba siendo infructuoso debido a la globalización de los estudios literarios, mediante la cual se acaba seleccionando mayormente textos occidentales en los cursos académicos, donde se utilizan antologías, que aunque incluyan textos de otros continentes, estos se acaban enseñando en un contexto de relaciones de poder en los que ocupan una posición marginal (2000: 38).

4. Véase Edward Said (1978: 681) y Abdul R. JanMohamed (1983: 4).

5. En este sentido, la literatura y teoría postcolonial comparten múltiples áreas de interés con otras teorías como el postmodernismo, el feminismo y los nuevos enfoques marxistas. De hecho, el discurso postcolonialista ha expandido su alcance hasta otras categorías discursivas como las de los grupos minoritarios (homosexualidad, feminismo, raza, etc.) y las ha incorporado a su discurso para generalizar y describir estructuras de poder jerarquizantes dentro de las sociedades hegemónicas. Por ejemplo, desde finales del siglo XX la temática de muchas novelas latinoamericanas se cimenta en la confección de la identidad y se caracterizan por reestablecer unas prácticas tradicionales en medio de un cambiante imaginario nacional y continental marcado por los efectos de la globalización. En la escritura resultante de esta confluencia, según Carmen Perilli, debido a que la globalización erosiona la localidad, el escritor usa su yo narrativo para imponer su memoria por encima de la historia "el pasaje filiación/afiliación se formula de modo peculiar en la búsqueda de la identidad(es) del sujeto" (2009: 51).

6. Jürgen Habermas señala la relevancia histórica de este momento mostrando que el discurso de la modernidad se ha esforzado por debilitar las fuerzas de unión social y suplantarlo con "the deformations of a one-sidedly rationalized everyday praxis which evoke the need for something equivalent to the unifying power of religion. Some place their hope in the reflective power of reason" (1987: 139). Sin embargo, en el contexto contemporáneo, según 
explica Jesús Martín-Barbero, desde el ultimo cuarto del siglo XX la hegemonía de la identidad nacional ha experimentado un desafío que ha provocado un "descentramiento de lo nacional" (1999: 302-03). Enfocándose en el Chile contempoáneo, Sara Sofía Correa Sutil afirma que el concepto de identidad nacional ha sido desechado en la actualidad por la mayoría de los intelectuales de su país. Yendo incluso más allá, Correa Sutil afirma que "estudios empíricos realizados en esta década del 2000 muestran una población refractaria a reconocerse en una identidad chilena común" (2009: 11).

7. Según expone Leah Greenfeld (1992), Inglaterra constituía un caso especial, ya que en Francia se siguió admirando a los filósofos y pensadores británicos por su papel fundamental en el impulso de la revolución industrial, pero se obvió la fuerte tendencia a mantener las tradiciones de ciertos sectores de una sociedad que se mostraba muy reacia al cambio en aspectos extra-industriales.

8. Según Foucalt, el discurso es utilizado por las sociedades fuertes para imponer sus valores y visión de la "verdad" a las más débiles a través de las instituciones y materias. Las naciones que poseen poder militar y económico adquieren el control del "conocimiento" actual e incluso futuro y ejercen su poder sobre las demás naciones y lo transmiten de forma indirecta en la literatura mediante la introducción de conceptos como la universalidad cultural (1977: 8-9).

Abdul R. JanMohamed, aunque en el contexto del tercer mundo, ha observado que este procedimiento es compartido por las sociedades marginales en procesos de crisis identitarias debido a que: "Even the very option to emulate the European puts the native in a double bind: if he chooses conservatively and remains loyal to his indigenous culture, then he opts to stay in a calcified society whose developmental momentum has been checked by colonization. If, however, the colonized person chooses assimilation, then he is trapped in a form of historical catalepsy because colonial education severs him from his own past" (1983: 5).

10. Como ya ha observado José Álvarez Junco, la situación de atraso en que se encontraba la España de comienzos del siglo XIX era evidente e incluso estaba fomentada por las autoridades: "The 94 per cent illiteracy rate bequethed by the absolute monarchy to modern Spain was no source of shame to the signatories of the 'Persian Manifesto' (conservative deputies hostile to the 1812 liberal constitution of Cadiz), who explicitly praised political systems which kept the people in the dark" (1996: 46).

11. Según Anderson, el florecimiento de la novela y de la prensa periódica proporcionan una estructura propicia para la configuración de la "comunidad imaginada" que constituye una nación: "For these forms provided the technical means for 're-presenting' the kind of imagined community that is the nation" (1991: 24-25). En la segunda mitad del siglo XIX las exigencias de un público más heterogéneo habían logrado el desarrollo de una mentalidad de mercado en la industria de publicación. Françoise Perus explica que aunque leer no esté ligado necesariamente a consumir, la globalización literaria está ligada al mercado de difusión y venta de los libros, lo cual hace inevitable la desconexión de lectura y consumo (11)

12. Francisco Caudet ha señalado cómo Emilia Pardo Bazán proponía que se siguieran los modelos rusos para "hacer una novela auténticamente nacional, insuflando ingredientes 'espirituales' en el naturalismo" (1988: 68).

13. Juan Pan-Mantojo afirma que en 1900 España era un país eminentemente agrario. Según Pan-Mantojo, en el censo de ese año, el $70 \%$ de los trabajadores eran agricultores y vivían en pueblos de menos de 5.000 habitantes. En esa época, la agricultura, junto con la minería representaba la mitad del producto nacional bruto (1998: 264).

14. Según Jesús Torrecilla, esta resistencia provoca un sentimiento ambivalente debido a que "la reacción defensiva de tipo nacionalista se fundamenta por una parte en el convencimiento de que el progreso es positivo, y por eso se imita; pero la imitación en sí se piensa que pone en peligro el carácter nacional y provoca una reacción hacia los componentes de la identidad propia" (1996: 51). Por otro lado, Juan López Morillas afirma que el origen de esta resistencia radica en su origen extranjero: "[Los tradicionalistas españoles] no aborrecían lo francés por el simple hecho de ser francés, sino de ser forastero; e idéntica, sin duda, hubiera sido la actitud si, en vez de ser gálica la cultura influyente, hubiera sido italiana o inglesa" (1956: 110). En el contexto de México, Gustavo Guerrero ha estudiado el grupo de escritores que han obtenido notoriedad en los últimos veinte años y percibe en ellos un deseo de polemizar la uniformidad del nacionalismo y de denunciar una maquinaria impositiva del poder que previene el desarrollo orgánico de la democracia (2012: 74). Guerrero explica que estos escritores cuestionan los componentes de la tradición que 
supuestamente configuran la identidad mexicana, descubriendo así nuevas posibilidades de conceptuar nuevos constituyentes identitarios o revisar elementos antes obviados, ocultados, perseguidos o ignorados por "el proyecto centralista del Estadonación moderno" (2012: 75). En el contexto de Cuba, Elzbieta Sklodowska explica que a causa de su aislamiento político y económico, la nación caribeña había logrado resistir la globalización de forma más o menos intacta hasta las últimas dos décadas, cuando se ha iniciado la etapa "post-soviética", la cual se ha visto marcada por la proyección internacional de la cultura cubana a través del film Fresa y chocolate, el fenómeno "Buena Vista Social Club," y el reconocimiento global de algunos escritores cubanos (2010: 105).

15. Los alemanes habían pasado por el mismo proceso un siglo antes cuando habían adoptado modelos ingleses para combatir su propia dependencia de Francia.

16. La repentina admiración por la cultura alemana ha sido estudiada por Egon Schwarz, para quien el krausismo en España fue una doctrina que en el fondo resultó mal entendida y fue incorrectamente interpretada (1965: 21).

17. Así sucede en Larra, Galdós, Alarcón o Valera, entre otros.

18. Véanse mis ensayos sobre Emilia Pardo Bazán, Baroja y Azorín.

\section{Referencias}

Álvarez Junco, José. 1996. The Nation-Building Process in Nineteenth-Century Spain. Nationalism and the Nation in the Iberian Peninsula. En Molinero \& Smith (eds.): 89-106.

Anderson, Benedict. 1991. Imagined Communities: Reflections on the Origin and Spread of Nationalism. London: Verso.

Calinescu, Matei. 1987. Five Faces of Modernity. Durham: Duke UP.
Caudet, Francisco. 1994. Clarín y el debate sobre el Naturalismo en España. En NRFH (XLII): 507-584.

Caudet, Francisco. 1988. La querella naturalista: España contra Francia. Realismo $y$ naturalismo en España en la segunda mitad del siglo XIX. En Lissorgues (ed.): 58-74.

Cedeño, Jeffrey. 2006. Un nuevo Borges: Literatura y globalización en América Latina. Iberoamericana, 6(24): 43-61.

Correa Sutil, Sofía. 2009. Identidad y globalización. Atenea (499): 11-32.

Dirlik, Arif. 1994. The Postcolonial Aura: Third World Criticism in the Age of Global Capitalism. Critical Inquiry. 20(2): 328-356.

Foucalt, Michel. 1971. Orders of Discourse. En Social Science Information, 10(2): 7-30.

GómezMadrid, Benito. 2013. Lamedievalización de La voluntad. Bulletin of Spanish Studies (XC.8): 1269-1289.

2012. El impresionismo místico de Camino de perfección. En Castilla: Estudios de literatura. (3): 137-158.

2007. Las ambivalencias del triángulo nacionalista de Insolación. Alba de América. (49/50): 151-66.

Guerrero, Gustavo. 2012. Literatura, nación y globalización en Hispanoamérica: Explorando el horizonte post-nacional. Revista de Estudios Hispánicos, 46(1): 73-81.

Greenfeld, Liah. 1992. Nationalism: Five Roads to Modernity. Cambridge: Harvard UP. 
Habermas, Jürgen. 1987. The Philosophical Discourse of Modernity: Twelve Lectures. Frederick Lawrence (trans). Cambridge: MIT Press.

Hassan, Waïl S. 2000. World Literature in the Age of Globalization: Reflections on an Anthology. College English, 63(1): 38-47.

JanMohamed, Abdul R. 1983. Manichean Aesthetics: The Politics of Literature in Colonial Africa. Amherst: $\mathrm{U}$ of Massachusetts Press.

López Morillas, Juan. 1956. El krausismo español: Perfil de una aventura literaria. México: Fondo de cultura económica.

Martín-Barbero, Jesús. 1999. Las transformaciones del mapa: identidades, industrias y culturas. América Latina, un espacio cultural en el mundo globalizado. En Garretón (ed.): 296-321.

Ortega y Gasset, José. 1983. Sobre los Estados Unidos. En Obras completas (4): 1963-83.

Otis, Laura. 1994. Organic Memory: History and the Body in the Late Nineteenth and Early Twentieth Centuries. Lincoln: U of Nebraska P.

Pan-Mantojo, Juan. 1998. "El atraso económico y la regeneración." Más se perdió en Cuba:
España, 1898 y la crisis de fin de siglo. En Pan-Mantojo (ed.): 261-334.

Perilli, Carmen. 2009. Fijando sombras: Una narrative en busca de autores. Revista de Crítica Literaria Latinoamericana, 35(69): 51-67.

Perus, Françoise. 2009. "Leer no es consumir (La literatura latinoamericana ante la globalización)." Revista de Crítica Literaria Latinoamericana 35(69): 11-31.

Said, Edward W. 1978. The Problem of Textuality: Two Exemplary Positions. Critical Inquiry 4(4): 673-714.

Schwarz, Egon. 1965. The Reception of German Culture in Spain. En Yearbook of Comparative and General Literature (14): 16-36.

Sklodowska, Elzbieta. 2010. Sin embargo: La literatura cubana y su crítica en la época de la globalización. Romance Notes, 50(1): 105-115.

Spivak, Gayatri Chakravorty. 1990. Poststructuralism, Marginality, Postcoloniality and Value. Literary Theory Today. En Collier \& Geyer-Ryan (eds.): 219-44.

Torrecilla, Jesús. 1996. El tiempo y los márgenes: Europa como utopía y como amenaza. Chapel Hill: U of North Carolina.

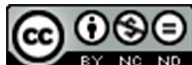

Este obra está bajo una licencia de Creative Commons Reconocimiento-NoComercial-SinObraDerivada 4.0 Internacional. 